\title{
Stalemate and 'DTS' depth to stalemate endgame tables
}

Article

Accepted Version

The article

Müller, K. and Haworth, G. (2020) Stalemate and 'DTS' depth to stalemate endgame tables. ICGA Journal, 41 (4). pp. 191199. ISSN 1389-6911 doi: https://doi.org/10.3233/ICG-190133 Available at https://centaur.reading.ac.uk/86343/

It is advisable to refer to the publisher's version if you intend to cite from the work. See Guidance on citing.

Published version at: https://content.iospress.com/articles/icga-journal/icg190133

To link to this article DOI: http://dx.doi.org/10.3233/ICG-190133

Publisher: The International Computer Games Association

All outputs in CentAUR are protected by Intellectual Property Rights law, including copyright law. Copyright and IPR is retained by the creators or other copyright holders. Terms and conditions for use of this material are defined in the End User Agreement.

\section{www.reading.ac.uk/centaur}

\section{CentAUR}

Central Archive at the University of Reading

Reading's research outputs online 


\title{
Stalemate and 'DTS' Depth to Stalemate Endgame Tables
}

\author{
Karsten Müller and Guy Haworth ${ }^{1}$ \\ Hamburg, Germany and Reading, UK
}

\begin{abstract}
Stalemating the opponent in chess has given rise to various opinions as to the nature of that result and the reward it should properly receive. Here, following Lasker and Reti, we propose that 'stalemate' is a secondary goal, superior to a draw by agreement or rule - but inferior to mate. We report the work of 'Aloril' who has created endgame tables holding both 'DTM' depth to mate and 'DTS' depth to stalemate data, and who should be regarded as the prime author of this paper. Further, we look at the classification of 'Chess Stalemate Studies' in the context of a 'Lasker Chess' which recognises the stalemate goal.
\end{abstract}

The question of what should be the appropriate reward for stalemating the opponent has given rise to various opinions over the centuries (Haworth, 2014). A comprehensive bibliography of sources on the subject would be a valuable resource in itself but here, we merely refer to past reviews and more specifically relevant articles. Section 1 surveys past and current perspectives on the subject while section 2 is our recommendation defining stalemating as a goal to be aimed at and rewarded.

Section 3 describes the achievements of 'Aloril' in creating 'EGT' endgame tables providing data on both forced mate and forced stalemate. The authors were inspired to revisit the subject of stalemate by his work. Indeed, 'Aloril' would be the first name on the author-line had he not wished to preserve his anonymity on the web. ${ }^{2}$

Section 4 reassesses 'stalemate studies' in the Lasker context of stalemating being a higher goal than otherwise drawing. Finally, we summarise and look forward.

\section{Perspectives on Stalemate}

Winter (1999) quotes the old rule from Philidor (1803): "The player giving the other the stale is, by a rule immemorially acquiesced in, adjudged to have defeated himself." This perspective goes back to Saul (1614) and was the penalty for having the game 'come to its end before the arrival of the regular result'. The rules of chess were first harmonised by the London Chess Club laws of 1807 (Hooper and Whyld, 1992, p388) to facilitate inter-club and international events. At that time, stalemate became a draw and it remains so today.

However, Lasker (1926; Nickel, 2013; Reti, 1926) expressed some frustration that stalemate was only a draw, citing, e.g., the endgame KBP-K with the bishop not controlling the conversion square, see Table 2. Later, Aronian (2017) and Kaufman were of the same opinion (Wikipedia, 2019). Lasker proposed 0.8 for stalemate.

\footnotetext{
${ }^{1}$ Communicating author: g.haworth@ reading.ac.uk

${ }^{2}$ His solving of $3 \times 3$ chess and his operational management of TCEC events deserve to be better known.
} 
Nigel Short (Lillebo, 2014a-2014c) argued that stalemate should be rated as a full one-point win. Indeed, if the rules of chess did not, with specific deference, disallow the capture of the King, all stalemates would be wins unless there were no physical moves available.

\section{The recommendation here: Lasker Chess}

The authors here take the view that:

- stalemating does not achieve as much as mate: it is therefore a lesser goal,

- stalemating should not be penalised as a loss: that view was rightly rejected in 1807 ,

- stalemate is a different kind of result from a draw: one side is reduced to inactivity,

- the side stalemating should be rewarded rather than penalised for achieving this,

- achieving stalemate should therefore receive an award $s$ in the range $1 / 2<s<1$, and

- the value of $s$ is debatable but of secondary interest: for simplicity, we suggest $s=3 / 4$.

We note the following benefits in support of but not as part of the logic above:

- stalemate leaves something to play for in a relatively drawn situation,

- a meaningful, finer-grained scale of achievement is in principle more informative,

- with chess as the analogy of a battle, stalemate is 'laying siege' but not total victory,

Murray (1913, p461) notes that de Lucena ( 1497) proposed that stalemate should be a half-win. Nevertheless, honouring the more familiar name of Lasker, an early champion of the stalemate-win, we prefer the name 'Lasker Chess' which was given by Nickel (2013) to the game of Chess with this new scoring system. While the other rules of the board and of play are the same, the new scoring system certainly affects the style of play and therefore creates a new variant of chess.

For the avoidance of fractions in Lasker Chess scoring, $0-1 / 2-1-1 \frac{1}{2}-2$ can scale to $0-1-2-3-4$ as used in Table 2 below. Similarly, 0-1/2-1-2-3 can scale to 0-1-2-4-6. Appendix B discusses more sophisticated scoring systems and obviates the need for the reader to do any further arithmetic.

\section{Aloril's Stalemate Endgame Tables}

Aloril recognised 'stalemate' as a goal, secondary to mate, which can be forcibly achieved by one side or the other. He also recognised that:

if all endgame positions have been identified from which a goal $G_{m a t e}$ can be achieved,

positions can then be identified from which a lesser goal $G_{\text {stalemate }}$ ' $<G_{\text {mate }}$ ' is achievable.

Both mate and stalemate terminate the game. Therefore, the algorithm for identifying all forced stalemates is almost identical to that which identifies all forced mates.

If one can move from a position in endgame $E$ to a 'successor' position in endgames $E_{1}, E_{2}, \ldots, E_{n}$, the EGTs for the endgames $E_{i}$ must be computed before that for $E$. The terminal positions of stalemate in endgame $E$ are identified and given depth $d t s=0$ ply. The set of positions $C$ in $E$ from which the stalemater can move (or the stalematee cannot avoid moving) to a forced stalemate in some endgame $E_{i}$ are noted with the appropriate depth $d t s$ which may be superseded later.

Once positions of depth $d t s=d$ have been noted, positions of depth $d+1$ may be identified, including the ' $d t s=d+1$ ' positions still in $C$ at that time. This may be done by examining all remaining positions 
(Nalimov et al, 2000) to discover those from which the stalemater can move to a position with $d t s=$ $d$ or the stalematee cannot avoid being stalemated in $d$ or fewer ply. However, the 'retrograde' method is almost always more efficient, stepping back from the 'frontier' of identified positions with $d t s=d$ ply to find positions with $d t s=d+1$ ply.

Aloril duly created sub-6-man 'EGT' endgame tables which provide both the well-known 'DTM' Depth to Mate information but also, with less than $40 \%$ extra time, 'DTS' Depth to Stalemate information. His work was independent of the work of Bungart (2013) who produced stalemate EGTs for some sub-6-man endgames. ${ }^{3}$ This was not known to Aloril at the time but the latter confirmed Bungart's maxDTS and maxDTS-position results in the domain they both addressed. That confirmation is one of our ancillary files.

Aloril proposes that, when playing Lasker Chess, EGTs with only stalemate information may complement existing DTM(ate) (Nalimov, 2000) or DTZ ${ }_{50}{ }^{\prime \prime}$ EGTs (de Man et al, 2018; Guo, 2018). Some $2 \%$ of sub-6-man positions can lead to stalemate, see Table 2 , and the $d t$ depth to stalemate ${ }^{4}$ can be considerable. EGT sizes are in total some $4 \%$ the total size of the equivalent DTM EGTs.

The e-repository version of this article (Müller and Haworth, 2020) provides comprehensive statistical and chess data - both for all physical positions and, after considering symmetries on the board, for all essentially different positions. The number of side-to-move 'forced stalemate' wins and losses of ply depth $d$ is given, together with a DTS-minimaxing line for a maxDTS position. Table 1 highlights the 40 endgames with the deepest maxDTS stalemates and Fig. 1 illustrates maxDTS positions from the five deepest of these.

Table 1. Counts of unique maxDTS stalemates with depths $d t s$ in ply: the 40 deepest endgames plus 4 others - KNNk, KPk, KNk and KBk. ${ }^{5}$

\begin{tabular}{|c|c|c|c|c|c|c|c|c|c|c|c|}
\hline$\#$ & $\begin{array}{c}\text { Endgame } \\
\text { force }\end{array}$ & $\begin{array}{l}\text { Stale- } \\
\text { mater }\end{array}$ & $\begin{array}{c}\text { \# } \\
\text { pos. }\end{array}$ & $\begin{array}{r}\text { dts, } \\
\text { ply }\end{array}$ & Example maxDTS FEN & \# & $\begin{array}{c}\text { Endgame } \\
\text { force }\end{array}$ & $\begin{array}{l}\text { Stale- } \\
\text { mater }\end{array}$ & $\begin{array}{c}\# \\
\text { pos. }\end{array}$ & $\begin{array}{r}d t s, \\
\text { ply }\end{array}$ & Example maxDTS FEN \\
\hline 01 & KQPkq & White & 3 & 210 & $3 \mathrm{q} 4 / 7 \mathrm{Q} / 2 \mathrm{~K} 5 / 8 / 7 \mathrm{k} / 8 / 4 \mathrm{P} 3 / 8 \mathrm{~b}$ & 23 & KQBkq & White & 5 & 83 & 8/1q6/8/8/8/8/2K4k/Q3B3 w \\
\hline 02 & KPPkp & White & 6 & 209 & 1K6/8/6p 1/8/8/8/P1k1P3/8 w & 24 & KBPkp & White & 4 & 82 & 2K5/8/7P/8/8/1B4p 1/8/k7 b \\
\hline 04 & KQPkp & White & 5 & 200 & 1K6/8/8/7Q/8/8/2k1P1p 1/8 b & 26 & KBPkq & White & 1 & 81 & q2B $4 / 4 \mathrm{P} 3 / \mathrm{k} 7 / 8 / 1 \mathrm{~K} 6 / 8 / 8 / 8 \mathrm{w}$ \\
\hline 05 & KRPkp & Black & 8 & 153 & 2K5/8/8/2P5/8/8/1R $1 \mathrm{p} 4 / 4 \mathrm{k} 3 \mathrm{~b}$ & 27 & $\mathrm{KBPkr}$ & Black & 6 & 81 & 8/8/8/8/3P4/1r6/6B1/K3k3 b \\
\hline 06 & KRPkq & Black & 20 & 152 & $2 \mathrm{~K} 5 / 8 / 8 / 2 \mathrm{P} 5 / 8 / 8 / 1 \mathrm{R} 6 / 3 \mathrm{qk} 3 \mathrm{w}$ & 28 & KNPkq & Black & 3 & 80 & 8/8/1KP5/8/8/7k/8/q4N2 w \\
\hline 09 & $\mathrm{KRPkr}$ & White & 3 & 110 & 8/7k/4r3/RK6/8/8/P7/8 b & 31 & KBPkp & Black & 2 & 73 & $2 \mathrm{~K} 5 / 8 / 8 / 2 \mathrm{P} 5 / 8 / 4 \mathrm{p} 2 \mathrm{~B} / 8 / 7 \mathrm{k} \mathrm{b}$ \\
\hline 10 & KBPkn & White & 2 & 106 & 8/8/n7/8/8/3K4/1P6/5B1k b & 32 & KBPkq & Black & 14 & 70 & $2 \mathrm{~K} 5 / 8 / 2 \mathrm{P} 5 / 8 / 8 / 7 \mathrm{~B} / 8 / 4 \mathrm{q} 2 \mathrm{k} \mathrm{w}$ \\
\hline 11 & KNNkp & White & 3 & 106 & $\mathrm{~K} 7 / 7 \mathrm{~N} / 8 / 2 \mathrm{p} 5 / 8 / 5 \mathrm{k} 2 / 7 \mathrm{~N} / 8 \mathrm{~b}$ & 33 & KRPkn & White & 11 & 70 & $\mathrm{~K} 7 / 8 / 8 / 7 \mathrm{k} / 8 / 5 \mathrm{P} 2 / 3 \mathrm{R} 4 / 2 \mathrm{n} 5 \mathrm{~b}$ \\
\hline 12 & KNPkp & White & 2 & 100 & $1 \mathrm{k} 6 / 8 / 6 \mathrm{P} 1 / 3 \mathrm{~K} 4 / 4 \mathrm{~N} 3 / \mathrm{p} 7 / 8 / 8 \mathrm{~b}$ & 34 & KNPkr & Black & 16 & 69 & 8/8/8/2k5/P6N/8/K7/1r6 b \\
\hline 13 & KNPkq & White & 2 & 97 & $1 \mathrm{k} 6 / 6 \mathrm{P} 1 / 8 / 3 \mathrm{~K} 4 / 4 \mathrm{~N} 3 / 8 / 8 / \mathrm{q} 7 \mathrm{w}$ & 35 & KPPkp & Black & 2 & 63 & 8/2P2P $2 / 1 \mathrm{~K} 6 / 8 / 8 / 8 / 6 \mathrm{p} 1 / 7 \mathrm{k}$ b \\
\hline 14 & KNPkn & White & 8 & 96 & 8/K7/n7/8/8/8/7P/k4N2 b & 36 & KPPkq & Black & 2 & 62 & $8 / 2 \mathrm{P} 2 \mathrm{P} 2 / 1 \mathrm{~K} 6 / 8 / 8 / 8 / 8 / 6 \mathrm{qk} \mathrm{w}$ \\
\hline 19 & $\mathrm{KRPkb}$ & White & 1 & 91 & 8/8/7R/8/3k4/5P $2 / \mathrm{K} 7 / 5 \mathrm{~b} 2 \mathrm{w}$ & 41 & KNNk & White & 6 & 52 & $8 / 7 \mathrm{~N} / 8 / 5 \mathrm{k} 2 / 8 / 8 / 8 / \mathrm{K} 6 \mathrm{~N} \mathrm{~b}$ \\
\hline 20 & KNNkn & White & 5 & 89 & $7 \mathrm{k} / 8 / 8 / 7 \mathrm{~N} / 8 / 2 \mathrm{~N} 5 / 3 \mathrm{~K} 4 / \mathrm{n} 7 \mathrm{w}$ & 42 & $\mathrm{KPk}$ & White & 21 & 42 & 8/8/8/8/8/1k6/7P/K7 b \\
\hline 21 & $\mathrm{KRBkr}$ & White & 34 & 85 & $8 / 2 \mathrm{R} 5 / 8 / 8 / \mathrm{k} 7 / 3 \mathrm{~K} 4 / \mathrm{r} 6 \mathrm{~B} / 8 \mathrm{w}$ & 43 & KNk & White & 9 & 27 & 8/8/8/8/8/1N6/8/1k1K4 w \\
\hline 22 & KNPkp & Black & 2 & 83 & 8/8/1K6/2P5/8/p6k/8/5N2 b & 44 & $\mathrm{KBk}$ & White & 37 & 17 & 8/8/8/8/8/8/8/2K1B1k1 w \\
\hline
\end{tabular}

\footnotetext{
${ }^{3}$ Bungert also produced entertaining stalemate data for 'endgames' involving zero or more than one king on a side.

4 ' $d t s$ ' denotes the depth of a specific position in the 'DTS' Depth to Stalemate metric.

${ }^{5} \mathrm{~A}$ 'maxDTS' position is one of maximum $d t s$ in its endgame; '\#pos' $\equiv$ the number of maxDTS positions.
} 
Table 2. Some endgames' percentage-distribution of the five results, White or Black to move. ${ }^{6}$

\begin{tabular}{|c|c|c|c|c|c|c|c|c|c|c|c|}
\hline \multirow{2}{*}{ \#\# } & \multirow{2}{*}{$\begin{array}{c}\text { Endgame } \\
\text { force }\end{array}$} & \multicolumn{5}{|c|}{$p \%$ distribution of wtm results } & \multicolumn{5}{|c|}{$p \%$ distribution of btm results } \\
\hline & & 4 & 3 & 2 & 1 & 0 & 0 & 1 & 2 & 3 & 4 \\
\hline 01 & KBk & 0 & 3.974 & 96.026 & 0 & 0 & 0 & 0.978 & 99.022 & 0 & 0 \\
\hline 02 & $\mathrm{KNk}$ & 0 & 1.476 & 98.524 & 0 & 0 & 0 & 0.255 & 99.745 & 0 & 0 \\
\hline 03 & $\mathrm{KPk}$ & 76.509 & 10.330 & 13.159 & 0.002 & 0 & 58.089 & 11.298 & 30.605 & 0.008 & 0 \\
\hline 04 & KQk & 100.000 & 0 & 0 & 0 & 0 & 89.691 & 0.401 & 9.908 & 0 & 0 \\
\hline 05 & KBkp & 0.002 & 0.890 & 93.864 & 0.003 & 5.240 & 0.001 & 0.130 & 74.953 & 1.343 & 23.574 \\
\hline 06 & KNkp & 0.004 & 0.142 & 86.889 & 0.031 & 12.934 & 0.001 & 0.016 & 66.028 & 1.392 & 32.563 \\
\hline 07 & KPkp & 43.416 & 4.472 & 26.614 & 2.262 & 23.235 & 23.235 & 2.262 & 26.614 & 4.472 & 43.416 \\
\hline 08 & KQkb & 99.694 & 0.002 & 0.303 & 0.001 & 0 & 76.879 & 0.005 & 22.881 & 0.235 & 0 \\
\hline 09 & KQkp & 99.367 & 0.622 & 0.010 & 0 & 0.001 & 80.172 & 0.951 & 9.780 & 1.348 & 7.748 \\
\hline 10 & KRkb & 35.189 & 2.077 & 62.733 & 0.001 & 0 & 3.241 & 1.090 & 95.434 & 0.235 & 0 \\
\hline 11 & KRkp & 91.434 & 0.536 & 7.862 & 0.002 & 0.166 & 66.099 & 0.789 & 15.366 & 1.349 & 16.397 \\
\hline 12 & KBPk & 95.950 & 2.769 & 1.281 & 0 & 0 & 83.220 & 4.248 & 12.532 & $\varepsilon$ & 0 \\
\hline 13 & KNNk & 0.010 & 99.354 & 0.636 & 0 & 0 & 0.002 & 81.366 & 18.632 & 0 & 0 \\
\hline 14 & KNPk & 96.297 & 0.314 & 3.389 & 0 & 0 & 81.505 & 1.541 & 16.954 & $\varepsilon$ & 0 \\
\hline 15 & KPPk & 98.386 & 1.033 & 0.580 & 0.001 & 0 & 92.086 & 3.700 & 4.210 & 0.004 & 0 \\
\hline 16 & KBPkb & 41.297 & 1.745 & 56.956 & $\varepsilon$ & 0.002 & 13.093 & 0.717 & 86.152 & 0.031 & 0.007 \\
\hline 17 & KBPkn & 56.620 & 2.310 & 41.067 & 0.002 & $\varepsilon$ & 26.972 & 1.368 & 71.650 & 0.008 & 0.002 \\
\hline 18 & KNPkn & 49.194 & 0.660 & 50.146 & $\varepsilon$ & $\varepsilon$ & 22.776 & 0.374 & 76.843 & 0.004 & 0.003 \\
\hline 19 & KPPkp & 77.084 & 1.351 & 8.572 & 0.355 & 12.638 & 53.240 & 2.057 & 15.927 & 1.094 & 27.681 \\
\hline 20 & KQPkq & 68.391 & 3.657 & 27.552 & 0.002 & 0.398 & 13.606 & 1.981 & 48.798 & 0.425 & 35.190 \\
\hline 21 & KRPkr & 66.575 & 1.366 & 31.643 & 0.008 & 0.408 & 25.541 & 0.852 & 53.287 & 0.248 & 20.072 \\
\hline
\end{tabular}
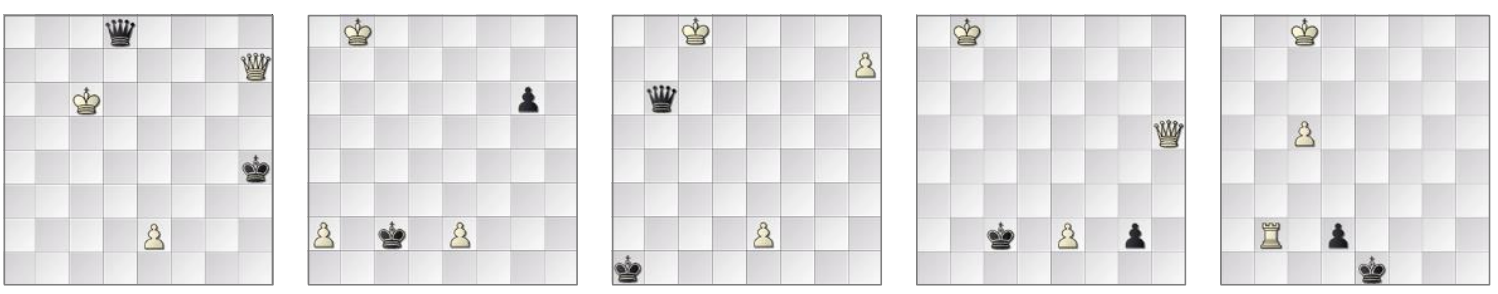

Fig. 1. maxDTS positions from the five DTS-deepest sub-6m endgames: (a) KQPKQ btm, 3-1, $d t s=210$ ply; (b) KPPKP wtm, 3-1, dts = 209 ply; (c) KPPKQ wtm, 3-1, dts = 201 ply; (d) KQPKP btm, 3-1, dts = 200 ply; (e) KRPKP btm, 1-3, dts = 153 ply (and after $1 . \ldots \mathrm{d} 1=\mathrm{Q}$, KRPKQ's maxDTS, wtm, 1-3, dts = 152 ply).

\section{4 'Lasker Chess' Studies}

The definitive database of chess studies is HHDBV by Harold van der Heijden (2015). The quality and scale of this work is extraordinary, an unmatched and continuing contribution to the Chess Studies community. ${ }^{7}$ HHDBV contains 85,619 studies of which 26,651 (31.13\%) are draw studies: White is challenged to find an effectively unique way to rescue the draw in an apparently lost position. Of these, $12,728(47.76 \%)$ end in stalemate in the main line, demonstrating that in the world of chess studies, stalemate is a major and attractive theme, perhaps because it brings a definitive end to the play. In contrast, only 0.34\% of over two million draws in CHESSBASE 2019 (Chessbase, 2018) end in stalemate. ${ }^{8}$ Fig. 2 gives the initial position for five of the authors' favourite stalemate studies, all

\footnotetext{
6 ' $\mathrm{wtm}$ ' ('btm') $\equiv$ White (Black) to move. A ' 3 ' win is a stalemate; a ' 1 ' is being stalemated. $\varepsilon$ : $0<\varepsilon<0.0005$.

${ }^{7}$ His aim is to publish HHDBVI in 2020.

${ }^{8}$ The precise Chessbase 2019 figures are: 7,625,216 games, 2,188,980 draws (28.71\%), 7,366 stalemates $(0.34 \%)$.
} 
from Beasley and Whitworth $(1996,2017)$. Some clues are provided in a footnote towards the end of this article. Wikipedia (2019) also gives examples from games.

A surprise is that of the 12,728 stalemate studies, only 326 (2.56\%) end in the mainline with White stalemating Black. Of these, over 30\% are flawed to some degree up to 'busted' ${ }^{9}$ in a Chess and/or Lasker Chess context. A first observation then is that the field of the chess study in which White delivers stalemate is a relatively unexplored one. Fig. 3 gives our choice of five stalemate studies where White stalemates Black, $3 \mathrm{~b}$ and 3c being from Selman (1991). ${ }^{10}$

The question arises as to the status of the many stalemate studies when considered as studies in Lasker Chess. They partition into three subsets: White or Black forcibly stalemates, or some side voluntarily chose to be stalemated to end the game. The chess study convention can and should carry over to Lasker Chess - White is challenged to find the effectively unique path to the best available but apparently unreachable goal, and to do so as quickly as possible.

Black should play its best frustrating move, hoping for an error by White. 'Flipping colours' when White is rescuing only $1 / 4$-point would likely lose the property of uniqueness for White's moves - but fortunately, it is not necessary to do so. There are further subtleties. Re-examining the corpus of draw studies could be a crowd project for the future and could reveal studies which did not end but could have ended with Black, or even White, stalemating. Note that the studies of Fig. $3 \mathrm{a}$ and $3 \mathrm{~b}$ lose the their 'dual' White moves in the more finessed world of Lasker Chess and sparkle, unflawed, under the Lasker sun.
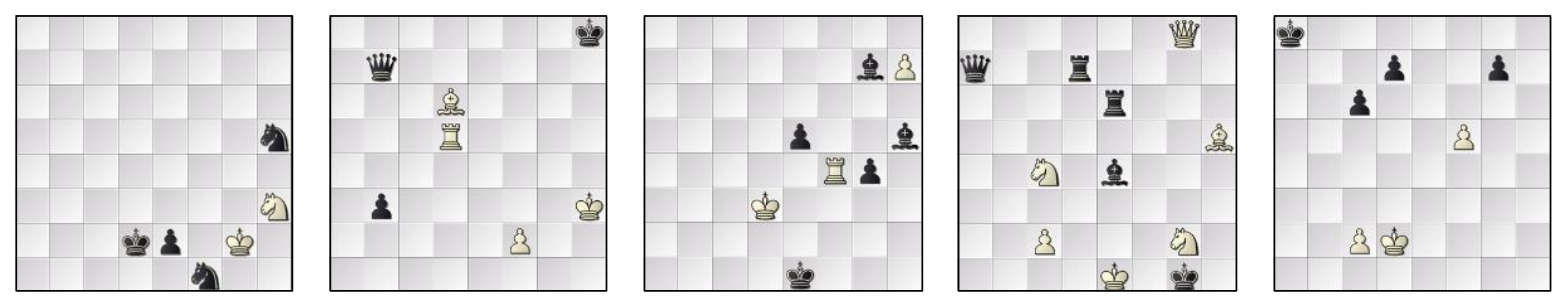

Fig. 2. Five '1-3' stalemates by Black: (a) Herbstman \& Kubbel (1937), (b) Kasparyan (1949),

(c) Roycroft (1958), (d) Lewandowski (1986) and (e) Lazard \& Zhigis (1986).
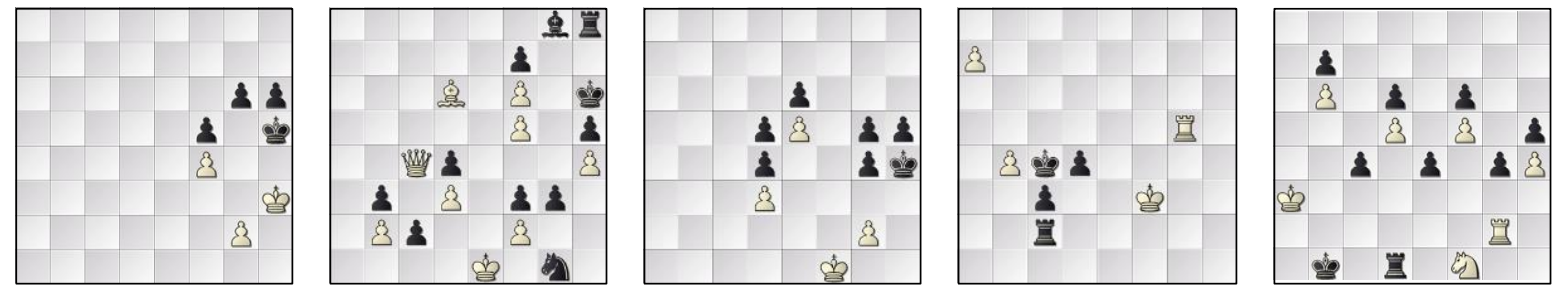

Fig. 3. Five '3-1' stalemates by White: (a) Mercier (1827), (b) Kasparyan (1931),

(c) Selman (1991), (d) Copie (2005) and (e) Khatmatov (2006) prefaced by Müller (2020).

Together, these ten studies illustrate a range of features, for example, the presence or absence of pins, blocks and self-blocks. Appendix A provides further comments on these concepts.

\footnotetext{
${ }^{9}$ HHdbV marks 'busted studies', where the aim is not achievable, with an '@3’ in the event tag value.

${ }^{10}$ Selman's 'Reciprocal Stalemate' concept does not survive in Lasker Chess: both sides would prefer to stalemate.
} 


\section{$5 \quad$ Reflection}

Here, we summarise, look forward and consider topics just outside the scope of this article.

The issue of how stalemate should be rewarded has given rise to every opinion across 500 years. Modern opinion tends to the view that stalemating is a positive rather than a negative achievement but less of one than mating. Like de Lucena, Lasker and Reti, we agree with this view and propose a score of $3 / 4$-point in the $0-1 / 2-1$ scoring system, or its equivalent in a scaled or similar system. Like Reti, we would like to see the 3/4-point on offer in tournaments. 'Number of stalemates' would effectively become the first tiebreaker before, e.g., Sonneborn-Berger and this would create a supplementary objective and more tension in drawish games.

Aloril recognised that endgame tables may be created to provide paths to more than one type of goal, in this case, to mate and then to stalemate. He has created 'DTS' Depth to Stalemate EGTs for all of sub-6-man chess and these can conveniently complement the existing DTM EGTs. The e-repository version of this article provides statistics, maxDTS positions and DTS-minimaxing lines from Aloril's complete results and these are available to be second-sourced. Further, we provide pgn files of chess positions and lines corresponding to Figures 1-4, Selman's studies and 'White stalemates' studies, all with the original expositions and supplementary analysis by the authors.

Our focus has been on the work of Aloril, creating endgame tables for chess as is but considering stalemate as a half-win. Just beyond our chosen scope, similar tables could be created if stalemate were considered equivalent to mate: these EGTs would include Aloril's stalemates but replace some mates with shorter stalemates. Further, if a null-move were required from stalemate, different EGTs would appertain and some stalemates would become mates - but deadlocks as in Fig. 3c would need to be managed. Readers whose primary interest and experience is not the domain of chess may care to consider and report on how any stalemate is or might be managed in their games.

We acknowledge and greatly value the earlier interest of Arno Nickel and his research into the topic of stalemate. He is a leading player of Correspondence Chess and is concerned about the increased incidence of draws. Further assistance came from John Beasley (2019) on Selman's work and from Michael Taktikos' (2019) Lasker Chess version of STOCKFISH. The various sub-8-man EGT-query services (Bleicher, 2019; de Man et al, 2018; Lomonosov, 2019) were invaluable as ever. With pleasure, we acknowledge and encourage the artistry and creativity of the many authors of Chess Studies. Some clues to the solutions of those in Figs. 2 and 3 are below. ${ }^{11,}$. More 'White stalemates' studies please! Finally, we thank the referees for their detailed observations which have contributed to this article.

\section{REFERENCES: all web-sources accessed on 2019-10-16}

Aronian, L. and Grigoryan M. (2017). https://tinyurl.com/icgaj064, especially 15'06" in. Levon Aronian interviewed by Meri Grigoryan. Chessbase.

Beasley, J. and Whitworth, T. (1996). Endgame Magic. Edition 2, Dover (2017).

Beasley, J. (2019). Private correspondence.

\footnotetext{
${ }^{11}$ Solution-clues for the studies of Fig. 2: (a) 2. Kh3, (b) 1. Be5, (c) 1. Rf5, (d) 1. Nge3 and (e) 1. Ke3 Kb7 2. Kf4.

${ }^{12}$ Solution-clues for the studies of Fig. 3: (a) 2. Kg3, (b) 2. fxg3, (c) 1. Kf2, (d) $1 . \mathrm{Nd} 2+$ and (e) 1. Ra2 Ra5.
} 
Bleicher, E. (2019). http://www.k4it.de/index.php?topic=egtb\&lang=en. Nalimov sub-7-man EGTs.

Bungart, M. (2013). Endspielanalyse für Lasker-Schach. M.Sc. thesis. Friedrich-Schiller-Universität, Jena.

Chessbase (2018). CHESSBASE 2019: a database of over 7.6 million games.

de Lucena, L.R. ( 1497). Repetición de Amores y Arte de Ajedrez con 101 Juegos de Partido.

de Man, R., Fiekas, N. and Guo, B. (2018). https://tinyurl.com/icga007. Fiekas' interface to 'Syzygy formatted' de Man sub-7-man and Guo 7-man DTZ 50 " EGTs.

Guo, B. (2018). ftp://ftp.chessdb.cn/pub/syzygy. EGT download site: sub-8-man DTZ50" EGTs.

Haworth, G.M ${ }^{\mathrm{c} C}$. (2014). Chess Endgame News. ICGA Journal, 37(3), 166-168. Supporting pgn file available from http://centaur.reading.ac.uk/38987/.

Hooper D. and Whyld, K. (1992). The Oxford Companion to Chess, $2^{\text {nd }}$ edition, pp387-8.

Lasker, E. (1926). Mein Wettkampf mit Capablanca, $2^{\text {nd }}$ ed. De Gruyter, Berlin and Leipzig.

Lillebo, P. (2014a). Stalemate: the long and the short of it. https://tinyurl.com/icga061. Chessbase.

Lillebo, P. (2014b). Stalemate: the long and the short of it, 2. https://tinyurl.com/icga062. Chessbase

Lillebo, P. (2014c). Stalemate: the long and the short of it, 3. https://tinyurl.com/icgaj063. Chessbase.

Lomonosov (2019). http://tb7.chessok.com/. Facility for querying sub-8-man DTM EGTs.

Müller, K. and Haworth, G.McC. (2020). http://centaur.reading.ac.uk/86343/. Stalemate and 'DTS' Depth to Stalemate Endgame Tables. doi: 10.3233/ICG-190133. This note plus core and supplementary data, pgn files and statistics.

Murray, H.J.R. (1913). A History of Chess. Skyhorse reprint, ISBN 978-1-62087-062-4 (2012). See also https://archive.org/details/AHistoryOfChess.

Nalimov, E.V., Haworth, G.M ${ }^{\mathrm{c}}$ C. and Heinz, E.A. (2000) Space-efficient Indexing of Chess Endgame Tables. ICGA Journal, 23(3), 148-162. See also http://centaur.reading.ac.uk/4562/.

Nickel, A. (2013). Die Unbesiegbaren: dem Fernschach droht der Remistod. Schach, no. 7, pp. 66-71, no. 8 , pp. $48-53$ and no. 10 , pp. $38-44$.

Philidor, A.N. (1803) Studies of Chess. London.

Reti, R. (1926). Modern Ideas in Chess, Ch. 6, essay 44 on 'Reform in Chess'. See also https://reluctant-messenger.com/chess/ebooks/Modern Ideas in Chess.pdf.

Saul, A. (1614). The famous game of Chesseplay. The first book in English on chess.

Selman, J. (1991). Reciprocal Stalemates (ed. Jan van Reek). Arves. ISBN 90-72939-08-5.

Taktikos, M. (2019). Private communication of analysis from 'Lasker Chess' STOCKFISH. van der Heijden, H.M.J.F. (2015). http://www.hhdbv.nl/. HHDBV, ENDGAME STUDY DATABASE V. Wikipedia (2019). Stalemate. http://en.wikipedia.org/wiki/Stalemate.

Winter, E. (1999). Stalemate. http://www.chesshistory.com/winter/extra/stalemate.html. 


\section{APPENDIX A: Some notes on annotation and stalemate studies}

Our move-annotation uses familiar symbols but in a quantitative rather than qualitative way. We are also annotating in the context of Lasker Chess rather than of Chess. '!!' and '!' indicate the only or best move preserving a 1/4-, 1/2-, 3/4- or 1-point value; '??' indicates a move which concedes value. ${ }^{13}$

Stalemate occurs when the side to move cannot do so because:

a) 'vs': the King cannot move to a vacant square without being in check,

b) 'b': the King cannot capture an opponent's man without being in check,

c) 'sb': the King cannot move to a square already occupied by one of its own men ${ }^{14}$,

d) ' $p$ ': some men cannot move as they are pinned against their King, and/or

e) 'bm': the men not pinned are blocked and have no move.

Each reader will have their own responses to the artistic and technical aspects of a line ending in stalemate. For convenience, we provide the 'vs-b-sb, p-bm' counts for many stalemates. Echoing the concept of a model mate where each vacant square is covered just once, we record the instances of a model stalemate where the same applies. Some miscellaneous notes on the studies follow.

Selman's (1991) interest was in 'Reciprocal Stalemate' studies in which separate lines end respectively in stalemate by White and Black. These lines largely diverge on a Black move as divergence on a White move constitutes a 'dual' flaw in studies. Therefore, Selman's selections are largely intrinsically '1-3' stalemates by Black as listed in our file b.pgn (Müller and Haworth, 2020): they are recast as such in our file s.pgn. Fig. 3b's Kasparyan study is a notable exception. Mario Garcia noticed that 2. $\mathbf{f x g} 3^{\prime \prime \prime \prime}$ leads to a ' $3-1$ ' stalemate by White and pre-empts the sideline $6 . . . \mathbf{g} \mathbf{1}=\mathbf{Q}$ '"' which leads to stalemate by Black. The flaw at position $2 \mathrm{w}$ is not a flaw in the context of Lasker Chess.

Fig. 2a's study won first prize in a tourney honouring Troitzky and features a classic Troitzky theme, three knights against one. It also demonstrates that Black should persist in pursuing the win. Fig. 2c: The Roycroft finale has the King surrounded on open ground with only one man pinned. Fig. 2d's Lewandowski study finishes with White's two knights pinned and its remaining piece blocked.

Fig. 3c's Selman study is rather similar to Fig. 3a's much earlier composition by Mercier but, because of the d-e pawns, which otherwise do not participate in the study, neither side has any move in the final position. This merely illustrates that the proposed 'null move' response to a stalemate position, as in Janggi, does not always continue the game as intended.

There have been some casualties along the way: some are listed in our file f.pgn, notably the 1946 'mirror stalemate' study by Liburkin (Hooper and Whyld, 1992, p261). It was awarded the first prize in a tourney but is in fact busted as Black can mate in 21 moves. ${ }^{15}$

Of the $326 \mathrm{HHDBV}$ 'White stalemates' listed in our file w.pgn, some 117 have one type of flaw or another with some fifty of these being relatively serious. Duals can and do disappear when stalemating and being stalemated are not equivalent. On the other hand, the stalemates of Chess did not need to be forced and are not necessarily so in Chess or Lasker Chess.

\footnotetext{
${ }^{13}$ Non-pgn files as here, allow a wider range of symbols: $" \prime \prime \equiv ! !, " \equiv !,{ }^{\prime} \equiv$ equi-optimal move, ${ }^{\circ} \equiv$ only legal move.

${ }^{14} \mathrm{We}$ do not consider a King self-blocked in this way if it could not move to that square in the absence of its own man.

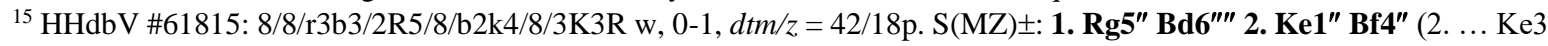

3. Kd1" Kd3"'" (3. ... Ra1+?? =); 2. ... Ra1+?? =) 3. Rgh5" Bg4" 4. Rh8" Be3" 5. Rd8+" Kc3" 6. Kf1" Bf3' 7. Rc8+" Kd3" 8. Rd8+" Bd4" 9. Rxd4+" Kxd4" (5m, dtm/z= 24/18p) 10. Rh7' Ke3"' 11, Re7+" Be4"' 12. Kg1" Rh6" ...
} 


\section{APPENDIX B: Lasker Chess - scoring systems and puzzles}

Chess has most commonly been scored on a $0-1 / 2-1$ basis though for the avoidance of fractions, we might scale this to $0-1-2$ or $0-6-12$. Where more aspirational play has been encouraged, a $0-1-3$ scoring has rated a win more merit-worthy than two draws, and this in turn could be scaled to 0-2-6 or 0-4-12.

The interpolation of scores given a stalemate result is simple enough if only linear interpolation is involved. Scoring the stalemate achievement as $3 / 4$, the appropriately enriched scaled scores become $0-3-6-9-12$ and 0-2-4-8-12. The avoidance of fractions involves somewhat larger integers for quadratic interpolation with the formula $b x(x+1) / 2$ in the $0-1-3$ case. The scores $0-6-12-18-24$ and the intriguing 0-3-8-15-24 are derived in rows 3 and 9 of Table 3.

Lasker also proposed 0.8 for stalemating the opponent, perhaps to rate two stalemates better than a win and draw. One might propose 0.7 to take the opposite view and it is worth noting that the '3/4/quadratic' scoring does exactly this. Either way, these scores seem an unnecessary sophistication, given that a player stalemating opponents twice in an event is very unlikely. For convenience, Table 3 exhibits the necessary arithmetic.

Table 3. Various scoring schemes for Lasker Chess, all normalised to 600 for a win.

\begin{tabular}{|c|c|c|c|c|c|c|c|c|c|c|c|}
\hline \# & Game & $\begin{array}{l}\text { Stalemate } \\
\text { Score }\end{array}$ & $\begin{array}{l}\text { 'Chess' } \\
\text { Scoring } \\
\end{array}$ & Interpolation & $\begin{array}{l}\text { 5-way } \\
\text { scores }\end{array}$ & $\begin{array}{c}\text { Scores for mate } \\
\text { and stalemate }\end{array}$ & $\begin{array}{c}\text { All ranged to } \\
\text { same figure for win }\end{array}$ & $\begin{array}{c}\text { Win }+ \\
\text { Draw } \\
\end{array}$ & $\begin{array}{c}\text { Two } \\
\text { S'mates } \\
\end{array}$ & $\Delta$ & \\
\hline 1 & Chess & 0.5 & $0-1-2$ & linear & $0-1-1-1-2$ & $0-1-1-1-2$ & $0-300-300-300-600$ & 900 & 600 & -300 & $<$ \\
\hline 2 & Lasker Chess & 0.7 & $0-1-2$ & linear & $0-0.6-1-1.4-2$ & $0-3-5-7-10$ & $0-180-300-420-600$ & 900 & 840 & -60 & $<$ \\
\hline 3 & Lasker Chess & 0.75 & $0-1-2$ & lit & $0-0.5-1-1.5-2$ & $0-1-2-3-4$ & $-150-300-450-600$ & 900 & 900 & 0 & $=$ \\
\hline 4 & Lasker Ch & 0 & $0-1-2$ & & $0-0.4-1$ & & 600 & 900 & 960 & 60 & $>$ \\
\hline 5 & Chess & & $0-1-3$ & linear & $0-1-1$ & -3 & $200-600$ & 800 & 400 & -400 & $<$ \\
\hline 6 & Lasker Chess & 0 & $0-1-3$ & linear & $0-0.6-1$ & $0-3$ & $0-120$ & 800 & 720 & -80 & $<$ \\
\hline 7 & Lasker Chess & 0.7 & $0-1-3$ & quadratic & $0-0.48-1-1.68-3$ & $0-12-25-42-75$ & $0-048-200-336-600$ & 800 & 672 & -128 & $<$ \\
\hline 8 & Lasker Chess & 0.75 & $0-1-3$ & linear & $0-0.5-1-2-3$ & $0-1-2-4-6$ & $0-100-200-400-600$ & 800 & 800 & 0 & $=$ \\
\hline 9 & Lasker Chess & 0.75 & $0-1-3$ & quadratic & $0-0.375-1-1.875-3$ & $0-3-8-15-24$ & $0-075-200-375-600$ & 800 & 750 & -50 & $<$ \\
\hline 10 & Lasker Chess & 0.8 & $0-1$ & & $0-0.4-1-2.2-3$ & $0-2$ & $0-080-200-440-600$ & 800 & 880 & 80 & $>$ \\
\hline 11 & Lasker Chess & 0.8 & $0-1-3$ & quadratic & $0-0.28-1-2.08-3$ & $0-7-25-52-75$ & $0-056-200-416-600$ & 800 & 832 & 32 & $>$ \\
\hline
\end{tabular}

Finally, we provide five stalemate puzzles with some clues below and full solutions in p.pgn, one of this article's supporting documents (Müller and Haworth, 2020).
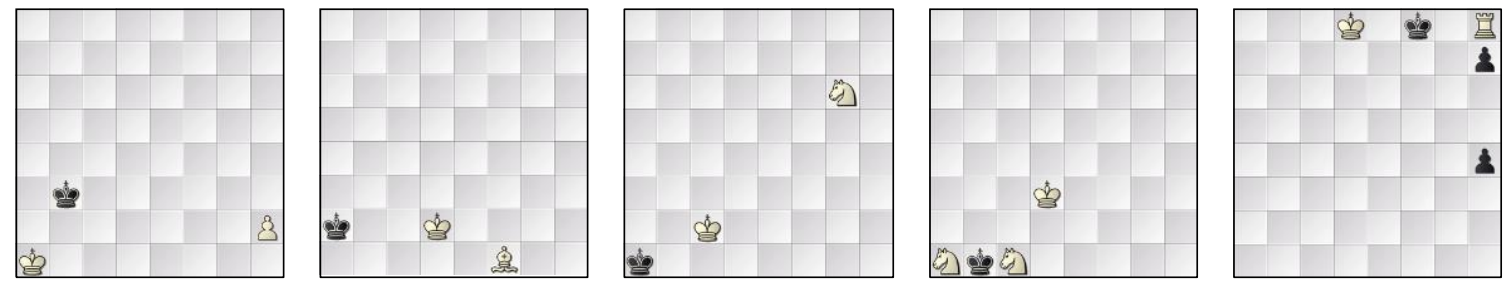

Fig. 4. Five puzzles, White stalemates in $m$ moves: (a) maxDTS KPk, btm, $m=21$; (b) KBk, wtm, $m=5$; (c) KNk, wtm, $m=5$; (d) KNNk, wtm, $m=5$; (e) maxDTS KRkpp, btm, $m=29 .{ }^{16}$

\footnotetext{
${ }^{16}$ Puzzle-clues: (b) 1. Kc3"'", (c) 2. Nc4"'" Ka1"', (d) 1. Kd2" Kb2" 2. Nc2", (e) 1. ... Kg7"'" 2. Re8"'" Kf6".
} 